\title{
Remembering Nils Nilsson
}

\author{
Karen Myers
}

Former President of the Association for the Advancement of Artificial Intelligence and Stanford University professor Nils Nilsson died on Thursday, April 23, 2020 after a long illness. In this tribute, his former student Karen Myers provides personal reflections on Nilsson and the lasting impact he had on her life, as well as Nilsson's contributions to the field of artificial intelligence. 


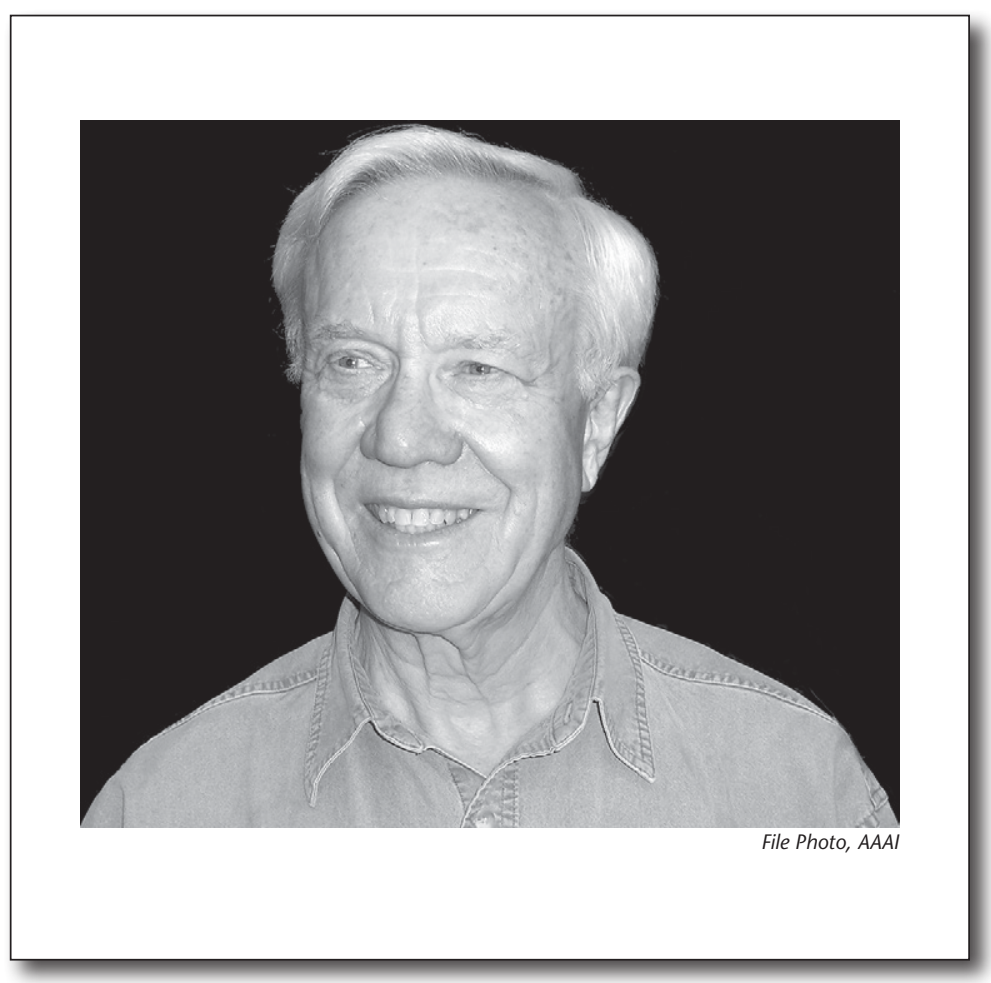

Figure 1. Nils Nilsson.

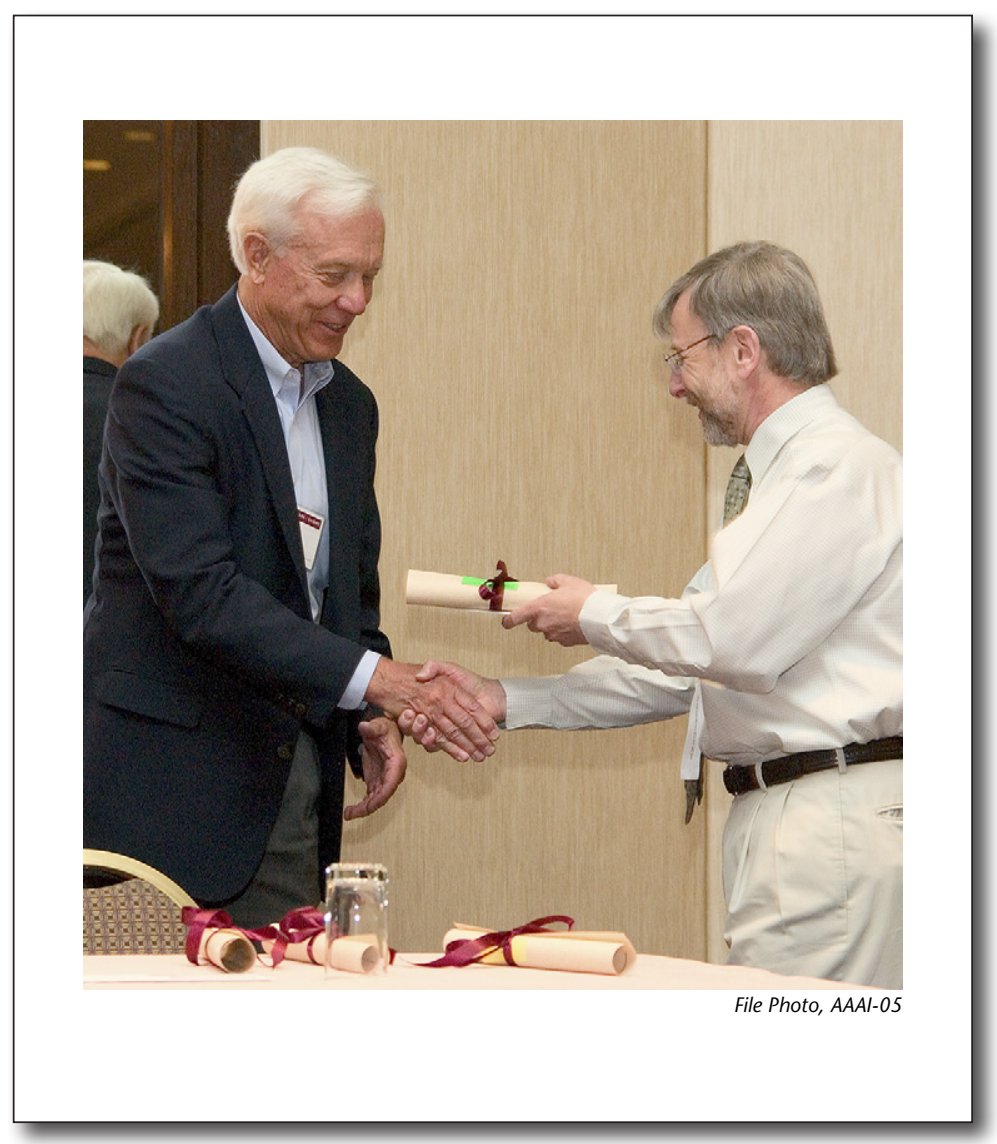

Figure 2. Nils Nilsson Received the AAAI Distinguished Service Award from AAAI President Ron Brachman in Pittsburgh, PA. machines that would dazzle the world with their breadth and scope of capabilities. I remember him warning his graduate students that we had better move quickly on our dissertations because he believed that major breakthroughs in AI were going to happen within five years and he didn't want us to miss out. While his timing was off by a couple of decades, he was correct about the impact that the field would have eventually. I'm so glad that he lived to witness the extent of the AI revolution that has occurred in recent years.

Researchers are notorious for learning more and more about less and less. In contrast, Nils made seminal contributions in almost all areas of AI. He started his career working on neural networks, then progressed to ground-breaking work on search, automated planning, robotics, logic, and hybrid probabilistic-deductive inference, landing on machine learning as the topic that fascinated him most late in his career. I recall him telling me around the time I graduated that he thought machine learning was the key to success for AI and, in typical fashion, he dove headlong into exploring its use to achieve his vision for intelligent robots.

The great outdoors was a second passion for Nils. He particularly loved to spend time at Lake Tahoe, frequently visiting a cabin that his family had co-owned with close friends for decades. We used to tease him about the frequency with which our Monday research meetings had to be cancelled during the winter because he had been snowed in yet again, leaving him no option but to spend another day skiing. Every spring break he invited his students to join him at the cabin for a few days. He was an expert skier but graciously passed on his favorite Black Diamond runs to help the novices navigate their way down the bunny hills. His former students have many fond memories of the cheery evening meals prepared and enjoyed together after our exertions on the slopes.

Nils deservedly was awarded every major accolade in the field, serving as a testament to his outstanding technical leadership and impact. I think what is even more special about him is how deeply he affected people on a personal level. His enthusiasm was infectious, and provided a level of optimism and energy that propagated readily to those nearby. His students and colleagues at both Stanford and SRI adored him. Almost without fail, the mention of his name brings a smile to people's faces and a fond story about some interesting shared experience or exchange with him. He is deeply missed. I'll be forever grateful for the many wonderful memories and the inspirational mentorship that he provided to me and so many other people in the AI community.

Karen Myers is the Director of SRI International's Artificial Intelligence Center, a position that Nils himself held for many years. She has a PhD in Computer Science from Stanford University and joined SRI at Nils' recommendation upon graduation. Her research interests include autonomy, multi-agent systems, planning, and intelligent assistants. 